\title{
Aplicação dos Recursos em Educação Básica: estratégias políticas em Goiás
}

\author{
Maria Cristina Dutra Mesquita \\ Pontifícia Universidade Católica de Goiás (PUC-Goiás), Goiânia/GO - Brasil
}

Maria Esperança Fernandes Carneiro

Pontifícia Universidade Católica de Goiás (PUC-Goiás), Goiânia/GO - Brasil

Lucia Helena Rincon Afonso

Pontifícia Universidade Católica de Goiás (PUC-Goiás), Goiânia/GO - Brasil

\section{Resumo}

Este artigo discute as políticas públicas do sistema educacional brasileiro e de Goiás, e dá destaque ao financiamento da educação como categoria de análise, estabelecendo um contraponto entre as leis que determinam regras para investimento em educação e as estratégias para o não cumprimento da legislação. As pretensas alterações legais e seus artifícios provocaram e ainda provocam o retrocesso da educação neste Estado, em relação ao financiamento.

Palavras-chave: Políticas Públicas da Educação. Financiamento. Educação Básica.

\section{Use of Resources in K-12 Education: political strategies in Goiás}

\section{Abstract}

This article discusses the public policies of the Brazilian and the Goiás state educational system, emphasizing the funding of education as the analysis category. It establishes a counterpoint between the laws that determine rules for investment in education and strategies for the non-compliance with the legislation. The alleged legal changes and their subterfuges have caused, and still do, the regression of education in this state in relation to the funding.

Keywords: Education Public Policies. Funding. K-12 Education. 
Aplicação dos Recursos em Educação Básica

\section{Introdução}

Este artigo resulta dos estudos sistemáticos acerca das políticas públicas de financiamento educacional do Brasil e de Goiás, bem como da aplicação dos recursos obrigatórios legais para a educação. Essa reflexão foi realizada a partir da análise das contas do Governo Estadual no período de 1997 a 2015, tendo como categoria de análise o financiamento da educação, determinante para a execução de ações propositivas para a educação em todos os níveis.

Os estudos realizados têm na pesquisa quantiqualitativa e na concepção dialética materialista sua fundamentação, que parte da necessidade da observação da realidade em seu movimento contraditório inscrito nas condições histórico-sociais de cada sociedade. Por isso, entendemos que a educação no capitalismo, no Brasil e, evidentemente, em Goiás está intimamente ligada às condições concretas para sua realização e, dessa forma, faz-se necessário compreender as contradições postas no interior da sociedade, que interferem, de forma significativa, nos resultados da educação, como as políticas públicas de financiamento.

A pesquisa empírica quantitativa foi utilizada como uma das possibilidades de estudos do nosso objeto e nos propiciou compreender as relações entre as políticas públicas, os recursos obrigatórios destinados à educação e as estratégias utilizadas para a aprovação das contas públicas.

Dividimos este estudo em dois momentos, sendo o primeiro uma rápida reflexão sobre as políticas de financiamento no Brasil e a relação com o cenário nacional no tocante à educação. Seguidamente buscamos analisar a situação educacional do Estado de Goiás que, no período estudado, apresenta alterações em relação ao percentual de recursos aplicados na Educação, opondo-se ao que prescreve a legislação maior.

\section{O Financiamento da Educação e o Panorama Nacional}

A educação brasileira vive um paradoxo, pois, após as lutas e conquistas que resultaram na garantia de um percentual fixo em 1988 (25\% dos recursos oriundos de impostos e transferências) para a oferta e a manutenção da educação, ainda deparamos com indicativos que sinalizam um descompasso na educação brasileira em relação à quantidade e à qualidade. Por um lado, as estatísticas indicam uma suposta universalização do Ensino Fundamental (um dos níveis de ensino que compõe a Educação Básica), porém a qualidade dessa educação oferecida no Brasil é bastante questionável. Vejamos alguns indicativos que nos remetem a uma necessária reflexão.

De acordo com a Pesquisa Nacional por Amostra de Domicílio (PNAD), realizada pelo Instituto Brasileiro de Geografia e Estatística (IBGE) em 2015, os brasileiros entre 25 anos ou mais apresentam um número médio de estudos de 7,9 anos, o que significa dizer que não conseguiram concluir o Ensino Fundamental, que é de 9 anos.

A escolaridade média da população de 25 anos ou mais de idade aumentou de 2005 a 2015, passando de 6,5 para 7,9 anos de estudo completos, o que, porém, ainda não equivale ao ensino fundamental completo [...]. É interessante observar que o Chile possuía uma média de anos de estudo de 7,3 em 1985 (HUMAN..., 2015), valor atingido pelo Brasil somente em 2011, isto é, um atraso de 25 anos em relação à escolaridade chilena, conforme aponta o Human Development Report (2014), publicado pelo 
Aplicação dos Recursos em Educação Básica

Programa das Nações Unidas para o Desenvolvimento - PNUD (United Nations Development Programme - UNDP) (BRASIL, 2016, p. 65).

Os dados referentes ao acesso ao Ensino Superior, nível II da educação brasileira, revelam que poucos brasileiros têm a oportunidade do acesso ao conhecimento historicamente produzido, exigido para permanência no mundo do trabalho. Diz a pesquisa:

O percentual da população de 25 a 64 anos de idade com ensino superior completo passou de $8,9 \%$ para $14,7 \%$ nesse período [...]. Esse aumento percentual da população adulta com ensino superior terá que se intensificar caso o Brasil queira se aproximar do percentual médio alcançado pelos países da $\operatorname{OCDE}^{1}(33,5 \%)$ e por países como o Chile (21,1\%) e o México (18,5\%) em 2014 (EDUCATION..., 2015) (BRASIL, 2015, p. 65).

A observância dos dados indicados pela síntese realizada pelo IBGE nos leva a dizer que quanto maior a faixa etária menor o número de anos de estudos a que o brasileiro teve acesso. Entretanto, é preciso atenção quando o governo alardeia a suposta universalização do ensino fundamental, por exemplo, quando observamos ainda a taxa de analfabetismo (população de 15 anos ou mais), que em 2015 foi de 8\%. Quando considerados os índices por grupos de idades, verificamos que o índice de analfabetismo para o grupo etário entre 65 anos ou mais é de $25,7 \%$.

Ao cruzarmos os dados referentes ao índice de analfabetismo e o rendimento familiar, vamos constatar que, embora o maior número de analfabetos esteja entre a população mais idosa, ao considerarmos o rendimento per capita (pessoas pertencentes ao $1^{\circ}$ quinto, ou seja, os mais pobres), a maior concentração de analfabetos está entre os mais novos:

A proporção de pessoas analfabetas com idade acima de 55 anos residentes em domicílios cujo rendimento domiciliar per capita fazia parte dos $20 \%$ com menores rendimentos era de apenas $28,6 \%$ em 2015 , logo a maioria desses analfabetos pertencia aos grupos etários mais jovens $(71,4 \%),[\ldots]$. Esses resultados são um retrato da dívida educacional brasileira, pois gerações de diferentes estratos de renda vivenciaram o acesso à educação de forma desigual (BRASIL, 2015, p. 66).

Bruno (1996, p. 98) recorda que "[...] a formação das novas gerações é um processo complexo que envolve várias esferas sociais e uma multiplicidade de instituições". Destas instituições, ela ressalta a esfera familiar e fundamentalmente a escola, ainda que o meio social e urbano seja o lócus de educação no sentido da sociabilidade do capital. Gerações que não conquistaram conhecimento suficiente que as qualificasse para exercer as tarefas requeridas pela tecnologia capitalista do seu tempo são gerações que se inserem no mercado de trabalho desvalorizadas, que receberão baixos salários ou estarão desempregadas, aumentando a marginalidade, constituindo-se em um segmento que tende a procurar subsistência na economia informal.

As formas precárias de trabalho e o desemprego são processos que, na maioria das vezes, alcançam aqueles com menor grau de escolaridade. Esses fatores aumentam o grau de risco "[...] entre camadas expressivas de jovens que tendem a reforçar a sabotagem aos processos de formação e a fomentar atos de violência contra as instituições" (BRUNO, 1996, p. 98), dentre elas a escola. Diferenças de investimentos na formação do custo aluno/ano/cidadão tão grandes, como é o caso do Brasil em relação aos países da

1 Organização para a Cooperação e Desenvolvimento Econômico. 
Aplicação dos Recursos em Educação Básica

Organização para a Cooperação e Desenvolvimento Económico (OCDE), no futuro corresponderão a salários e qualidade de vida segundo diferentes investimentos sociais e custos de formação. A formação/qualificação é tempo de trabalho investido nas qualificações que vão das primárias às mais complexas e que geralmente refletem na equivalência salarial.

A política educacional, por sua vez, retrata a política de Estado, cuja raiz, no caso do Brasil, está posta nas políticas neoliberais.

[...] o neoliberalismo questiona e põe em cheque o modo de organização social em que há uma grande intervenção e participação estatal, ou seja, o Estado do Bem-EstarSocial, ou Estado da Providência. Segundo Azevedo (1997), a máxima 'Menos Estado e mais Mercado' vai sintetizar o viés central do pensamento neoliberal, que se fundamenta sob a égide da liberdade individual, fortalecido por um estado minimalista para o social e máximo para o capital, com grandes incentivos à privatização, à desqualificação dos serviços públicos e das políticas públicas e na legitimação da teoria do capital humano, tornando o mercado cada vez mais restrito, competitivo, seletivo e elitizado (MESQUITA, 2010, p. 44).

É fato que a política neoliberal coloca os países em desenvolvimento reféns de seus pressupostos arbitrários, que inclui a constituição de um Estado mínimo, incentivando o afastamento do Estado da responsabilidade social para com a educação. Contraditoriamente, a Constituição Federal Brasileira de 1988 defende a educação como direito de todos e dever do Estado e da família. Dessa forma, é imprescindível a observação das obrigações estatais e a luta para a permanência da educação como direito de todos os cidadãos brasileiros, confirmando o que a Carta Magna diz no art. 205, cap. III.

Nessa conjuntura de neoliberalismo, ao analisarmos as políticas públicas para a educação no Brasil, o que se tem reforçado é um claro desmantelamento das instituições públicas de ensino e nos vemos diante de poucos recursos para muitas necessidades. Os diferentes programas oferecidos às escolas, seja por meio de celebração de convênios, seja em forma de repasses diretos, são marcados pela insuficiência de recursos, o que leva a um baixo impacto nas redes públicas há décadas. A exemplo dos Programas Nacionais de Alimentação Escolar - PNAE, Transporte Escolar, Dinheiro Direto na Escola, entre outros, que por muitos anos mantiveram o valor per capita inalterado.

A relação entre o Produto Interno Bruto - PIB e a educação é fruto de lutas intermitentes dos defensores da educação pública, no entanto, embora o índice tenha apresentado leve aumento nas últimas décadas, a situação no Brasil ainda está longe de alcançar o que prevê a Meta 20 do Plano Nacional de Educação, Lei n 13.005/2014 - 7\% do PIB até 2019 e 10\% até 2024 (BRASIL, 2014).

Em 2014 os investimentos públicos diretos ${ }^{2}$ na educação representaram 5\% do PIB. Nem todos os níveis e etapas de ensino tiveram crescimento quanto ao investimento em educação. A Tabela 1 traz o percentual de investimento por níveis de ensino:

2 São considerados investimentos diretos aqueles aplicados diretamente nas instituições de ensino, como, por exemplo, os utilizados para a aquisição de livros didáticos, merenda e transporte escolar, pagamento de professores, obras e instalações para a melhoria das escolas (BRASIL; MEC, 2008). 
Tabela 1 - Percentual do Investimento Público Direto em Relação ao PIB Brasil - 2000-2014

\begin{tabular}{|c|c|c|c|c|c|c|c|}
\hline \multirow{3}{*}{ Ano } & \multirow{3}{*}{ Total } & \multicolumn{6}{|c|}{ Níveis de Ensino } \\
\hline & & \multirow[b]{2}{*}{ Educação Básica } & \multirow[b]{2}{*}{ Educação Infantil } & \multicolumn{2}{|c|}{ Ensino Fundamental } & \multirow[b]{2}{*}{$\begin{array}{l}\text { Ensino } \\
\text { Médio }\end{array}$} & \multirow[b]{2}{*}{$\begin{array}{l}\text { Educação } \\
\text { Terciária }\end{array}$} \\
\hline & & & & $\begin{array}{l}\text { De } 1^{\mathrm{a}} \text { a } 4^{\mathrm{a}} \\
\text { Séries ou Anos } \\
\text { Iniciais }\end{array}$ & $\begin{array}{l}\text { De } 5^{\mathrm{a}} \text { a } 8^{\mathrm{a}} \\
\text { Séries ou Anos } \\
\text { Finais }\end{array}$ & & \\
\hline 2000 & 3,9 & 3,2 & 0,3 & 1,3 & 1,0 & 0,5 & 0,7 \\
\hline 2001 & 4,0 & 3,3 & 0,3 & 1,2 & 1,1 & 0,6 & 0,7 \\
\hline 2002 & 4,1 & 3,3 & 0,3 & 1,4 & 1,1 & 0,4 & 0,8 \\
\hline 2003 & 3,8 & 3,1 & 0,3 & 1,3 & 1,0 & 0,5 & 0,7 \\
\hline 2004 & 3,8 & 3,2 & 0,4 & 1,3 & 1,1 & 0,4 & 0,6 \\
\hline 2005 & 3,9 & 3,2 & 0,3 & 1,3 & 1,1 & 0,4 & 0,7 \\
\hline 2006 & 4,2 & 3,6 & 0,3 & 1,4 & 1,3 & 0,6 & 0,7 \\
\hline 2007 & 4,4 & 3,7 & 0,4 & 1,4 & 1,3 & 0,6 & 0,7 \\
\hline 2008 & 4,6 & 3,9 & 0,4 & 1,5 & 1,4 & 0,6 & 0,7 \\
\hline 2009 & 4,8 & 4,1 & 0,3 & 1,6 & 1,5 & 0,6 & 0,7 \\
\hline 2010 & 4,9 & 4,1 & 0,4 & 1,6 & 1,5 & 0,7 & 0,8 \\
\hline 2011 & 5,0 & 4,2 & 0,4 & 1,5 & 1,4 & 0,9 & 0,8 \\
\hline 2012 & 5,0 & 4,3 & 0,5 & 1,5 & 1,3 & 0,9 & 0,8 \\
\hline 2013 & 5,1 & 4,3 & 0,5 & 1,5 & 1,3 & 0,9 & 0,8 \\
\hline 2014 & 5,0 & 4,2 & 0,6 & 1,4 & 1,3 & 0,9 & 0,8 \\
\hline
\end{tabular}

Fonte: Diretoria de Tecnologia e Disseminação de Informações Educacionais (DTDIE) (BRASIL; MEC, 2008).

De acordo com Cury, o pacto federativo previsto na Emenda Constitucional $n^{\circ} 53$ de 2006 é necessário para o alcance da Meta 20 do PNE:

Articulado a este, está o desafio da sustentabilidade financeira do Plano Nacional de Educação. A referência ao PIB (chegar aos 10\% em dois tempos) é muito clara na emenda constitucional e na própria lei n. 13.005/2014. Tal sustentabilidade é crucial. Esta cláusula constitucional é condição de possibilidade para o sucesso do PNE. Sua não efetivação é mais um retorno ao fracasso dos PNE passados (CURY, s. d., p. 22).

Com investimentos aquém da necessidade para a oferta de uma educação que se espera para todos, as prioridades educacionais são decididas de acordo com os interesses de classe. O campo de lutas de classes se faz nas disputas pelo fundo público tensionado permanentemente pelas demandas de privatistas e defensores da educação pública, o que sempre nos impõe um alerta em relação às medidas provisórias e aos programas de governo, presentes sobretudo na atualidade. O resultado dessa política de escassez financeira compromete os resultados do processo ensino-aprendizagem de qualidade e a formação dos futuros trabalhadores. Essa estratégia de escassos recursos para qualificação de crianças e jovens é fator limitante na formação para a execução de trabalhos complexos.

\section{A Situação em Goiás: da conquista ao retrocesso}

A Constituição de 1988 legitima uma conquista da sociedade brasileira, quando, em seu artigo 212, diz que: 
Aplicação dos Recursos em Educação Básica

A União aplicará, anualmente, nunca menos de dezoito, e os Estados, Distrito Federal e os Municípios vinte e cinco por cento, no mínimo, da receita resultante de impostos, compreendida a proveniente de transferências, na manutenção e desenvolvimento do ensino (BRASIL, 1988, p. 1).

As reivindicações da classe trabalhadora, no que concerne aos recursos responsáveis pelo financiamento da educação, a começar pela Educação Básica, não foram alcançadas, uma vez que as ações governamentais indicam a tendência do afastamento do Estado, desde 2016, cada vez mais das políticas sociais, incluindo aqui a educação. Estudos indicam que:

O neoliberalismo, fomentador desta política de financiamento, vem conseguindo manobrar a opinião pública, em especial no que se refere ao atendimento à educação básica. Há uma equivocada difusão de que o investimento na Educação Básica tem propiciado um maior atendimento às crianças de 7 a 14 anos. Em relação a isso, o que se constata, paradoxalmente, é uma designação orçamentária, que vem sofrendo variações, comprovadamente para menor, como já foi apontado pelo relatório do Fundef (MESQUITA, 2005, p. 59).

Em relação à aplicação dos $25 \%$ resultantes da receita de impostos, que tanto os estados quanto os municípios devem utilizar na manutenção e no desenvolvimento da função ensino, o Estado de Goiás, por ocasião da elaboração da Constituição Estadual, apresentou avanço significativo nesse sentido. O art. 158 da Constituição de 1989 preconizava que:

O Estado aplicará, anualmente, no mínimo trinta por cento da receita de impostos, incluída a proveniente de transferências, na manutenção e desenvolvimento do ensino público, prioritariamente nos níveis fundamental, médio, pré-escolar e de educação especial (GOIÁS, 1989).

O governo do Estado homologa a Constituição aprovada em 5 de outubro de 1989 e, durante 14 anos (1989 a 2003), Goiás sustentará uma política de maiores recursos para a Educação Básica, embora a aplicação de recursos na educação não tenha respeitado essa conquista. A Lei de Diretrizes e Bases da Educação Nacional, LDBEN 9.394/96, (Brasil, 1996) reforça a vinculação do percentual de impostos para a educação (18\% União, 25\% Distrito Federal, Estados e municípios), bem como a LDB Estadual: Lei Complementar $n^{\circ} 26$ de 28 de dezembro de 1998 (GOIÁS, 1988).

Ao trazermos a Tabela 2, que evidencia a aplicação dos impostos e das transferências constitucionais na educação, reforçamos que a legislação à época não considerava como aplicação na educação as despesas com pagamento de servidores da educação inativos e pensionistas. Entretanto, no Relatório de Gestão enviado ao Tribunal de Contas do Estado de Goiás (TCE), os percentuais indicados aceitaram o pagamento dos salários dos servidores ativos, inativos e pensionistas, contrariando a CF de 1988 e a LC 26 de 1998. 
Tabela 2 - Percentual de Gastos com a Educação Básica Goiás 1997-2002 ${ }^{3}$

\begin{tabular}{|c|c|c|}
\hline Ano & $\begin{array}{c}\text { Percentual } \\
\text { aplicado }\end{array}$ & Observação \\
\hline 1997 & 31,08 & Não informa se consideraram inativos e pensionistas \\
\hline 1988 & 31,36 & Não informa se consideraram inativos e pensionistas \\
\hline 1999 & 26,90 & Não informa se consideraram inativos e pensionistas \\
\hline 2000 & 26,31 & Consideraram-se inativos e pensionistas \\
\hline 2001 & 28,46 & Consideraram-se inativos e pensionistas \\
\hline 2002 & 30,12 & Consideraram-se inativos e pensionistas \\
\hline
\end{tabular}

Fonte: Tribunal de Contas do Estado de Goiás.

Podemos observar que, a partir de 1999, quando se inicia a gestão de Marconi Perillo, os índices de aplicação de recursos previstos na legislação estadual foram desconsiderados, uma vez que esta determinava $30 \%$ deles oriundos de impostos e transferências constitucionais para a educação, com exceção do ano de 2002, último ano do seu primeiro mandato e também ano de eleições para o executivo estadual.

As conquistas sociais em Goiás começam a sofrer as primeiras perdas, do ponto de vista do financiamento, quando se aprova a Emenda Constitucional $n^{\circ} 33$ de 02 de janeiro de 2003, a qual revoga o Artigo 158, dando-Ihe nova redação:

O Estado aplicará, anualmente, no mínimo $28 \%$ (vinte e oito por cento) da receita de impostos, incluída a proveniente de transferências, em educação, destinando pelo menos $25 \%$ (vinte e cinco por cento) da receita na manutenção e no desenvolvimento do ensino público, prioritariamente nos níveis fundamental, médio e de educação especial e, os $3 \%$ (três por cento) restantes, na execução de sua política de ciência e tecnologia, inclusive educação superior estadual (GOIÁS, 2003).

A nova redação do referido artigo é homologada pelo então governador do Estado à época, que, utilizando manobra política, acaba por reduzir os investimentos na Educação Básica no Estado. Observa-se que a Educação Básica perdeu 5\% dos recursos conquistados por ocasião da Constituição Estadual em 1989 (anteriormente estavam destinados 30\% para o Ensino Fundamental, Ensino Médio e Pré-escolar), além de não atender ao Pré-escolar como previa a Lei anterior à $E C n^{\circ} 33$. A perda da aplicação de recursos $(5 \%$ do total destinado à educação) da Educação Básica de Goiás vai se explicitar claramente nos próximos anos nas médias de avaliação externa e interna decrescentes (MESQUITA; CARNEIRO, 2007).

A aplicação dos recursos na educação básica no Estado segue, nos anos seguintes, com índices abaixo do que a legislação determina. O descumprimento constitucional fica evidente nas contas de Governo, como mostra a Tabela 3:

Tabela 3 - Percentual de Gastos com a Educação Básica - Goiás 2003-2005 (\%)

\begin{tabular}{|c|c|c|}
\hline Ano & $\begin{array}{l}\text { Percentual aplicado incluindo } \\
\text { inativos e pensionistas }\end{array}$ & $\begin{array}{l}\text { Percentual aplicado exceto inativos e } \\
\text { pensionistas }\end{array}$ \\
\hline 2003 & 26,39 & 19,96 \\
\hline 2004 & 25,05 & 22,76 \\
\hline 2005 & 25,28 & 23,77 \\
\hline
\end{tabular}

Fonte: Tribunal de Contas do Estado de Goiás.

3 Foram consideradas as despesas pagas e a pagar no ano seguinte. 
Aplicação dos Recursos em Educação Básica

Cabe enfatizar que, ao desconsiderar o pagamento com servidores inativos e pensionistas, esses índices caem e não alcançam o mínimo exigido por lei, ou seja, $25 \%$. A análise do TCE em relação às contas de governo, nesse período, sequer menciona o descumprimento da lei, a qual vincula $25 \%$ da receita resultante de impostos à educação, excluindo o pagamento com inativos e pensionistas. A única ressalva apontada pelo Tribunal refere-se à aplicação de gastos em Ciências e Tecnologia e no Ensino Superior:

RESSALVANDO que houve descumprimento de parte do artigo 158 da Constituição Estadual, que fixa em $3 \%$ da receita de Impostos o valor a ser aplicado na execução da política de ciência e tecnologia, inclusive educação superior estadual, visto que o valor aplicado corresponde a 1,73\% (TCE, 2003, s. p.).

Apesar das ressalvas no Relatório de Contas, este é encaminhado à Assembleia Legislativa para julgamento e resta aprovado.

Em dezembro de 2005, a EC n 39 é aprovada na Assembleia Legislativa para alteração do art. 158 da Constituição Estadual. Dessa vez a intenção é devolver parte do percentual da receita de impostos e transferências retirados em 1989, destinados à educação, passando de $28 \%$ para $28,25 \%$. Preconiza o artigo:

O Estado aplicará, anualmente, no mínimo $28,25 \%$ (vinte e oito e vinte cinco centésimos por cento) da receita de impostos, incluída a proveniente de transferências, em educação, destinando pelo menos $25 \%$ (vinte e cinco por cento) da receita na manutenção e no desenvolvimento do ensino público, na educação básica, prioritariamente nos níveis fundamental e médio, e na educação profissional e, os 3,25\% (três e vinte e cinco centésimos por cento) restantes, na execução de sua política de ciência e tecnologia, inclusive educação superior estadual, distribuídos conforme os seguintes critérios:

I - 2\% (dois por cento) na Universidade Estadual de Goiás - UEG, com repasses em duodécimos mensais;

II - 0,5\% (cinco décimos por cento) na entidade estadual de apoio à pesquisa;

III - 0,5\% (cinco décimos por cento) no órgão estadual de ciência e tecnologia;

IV - 0,25\% (vinte e cinco centésimos por cento) na entidade estadual de desenvolvimento rural e fundiário, destinados à pesquisa agropecuária e difusão tecnológica (GOIÁS, 2005).

Além da alteração do percentual, a EC n. 39 traz nova destinação dos recursos. Dessa vez, além de permanecer excluída da destinação de verbas à educação pré-escolar, é também eliminada a educação especial ${ }^{4}$, sendo substituída pela educação profissional.

É importante ressaltar que a alteração de $0,25 \%$ da receita vincula-se por força de lei à pesquisa agropecuária e difusão tecnológica a que a $E C n^{\circ} 33$ não fazia menção. Não obstante a pesquisa nessa área tenha relevante importância em um Estado agropecuário, não se pode considerá-la como investimento na Manutenção e Desenvolvimento do Ensino MDE. Portanto, essa inclusão se dá em uma tentativa de quantificar um índice, ampliando um possível investimento em educação. Mais uma estratégia ideológica.

4 Embora tenha sido retirada da legislação, em 2005 o governo investiu, até o $6^{\circ}$ bimestre na Manutenção e Desenvolvimento da Educação Especial, o valor de $\mathrm{R} \$ 265.000,00$, o equivalente a $12,18 \%$ do total previsto. Não houve investimento na Educação Infantil (GOIÁS, 2005). 
Aplicação dos Recursos em Educação Básica

A nova redação também deixa clara a intenção de investimento do governo estadual em relação à Educação Superior, uma vez que fica destinado o percentual de $2 \%$ desses recursos para a Universidade Estadual de Goiás - UEG. Entretanto, os repasses mensais previstos em lei para a UEG não se realizaram na prática, conforme se evidencia a seguir.

Considerando a perda de recursos para o Ensino Fundamental, uma vez que o Estado declina de sua função primeira que é a oferta e manutenção da Educação Básica, esse fato constitui-se em uma derrota para a população goiana, uma vez que o Estado não tem obrigatoriedade de se ocupar do Ensino Superior. Nesse contexto, ainda podemos constatar que os recursos destinados por força de Lei à UEG não foram repassados na totalidade. Segundo a Lei $n^{\circ} 15.075$ de 11 de janeiro de 2005, que orça a receita e fixa a despesa do Estado para o exercício 2005, o Tesouro previu $\mathrm{R} \$ 4.996 .493 .000,00$ (receita tributária), além da receita de transferências. Desses recursos, 25\% para a Educação Básica e 3\% para o Fundo de Ciência e Tecnologia, diminuindo deste último percentual 2\% para a UEG.

Coube à UEG, considerando os $2 \%$, o valor previsto em orçamento de $\mathrm{R} \$$ 107.202.000,00, a serem repassados no ano de 2005 para cobrir as despesas correntes e capital da Universidade; no entanto, os valores orçados e as despesas realizadas diferem dessa previsão. A Tabela 4 evidencia os dados:

Tabela 4 - Despesas UEG custeadas pelo Tesouro Estadual 2005 - Por grupo e natureza de despesa

\begin{tabular}{|l|c|c|c|c|}
\hline \multicolumn{1}{|c|}{ Natureza Despesa } & Dotação atualizada \\
$(\mathrm{R} \$$ Mil) & $\begin{array}{c}\text { Despesa realizada até } \\
\text { o 6 }{ }^{\circ} \text { bimestre (R\$ Mil) }\end{array}$ & $\begin{array}{c}\text { Recurso } \\
\text { não } \\
\text { utilizado } \\
\text { (R\$ Mil) }\end{array}$ & $\begin{array}{c}\text { \% de } \\
\text { Execução }\end{array}$ \\
\hline Pessoal e Encargos Sociais & 44.489 & 41.755 & 2.734 & 93,10 \\
\hline Outras Despesas correntes & 20.967 & 3.947 & 17.020 & 18,82 \\
\hline Investimento & 39.645 & 3.059 & 36.586 & 7.72 \\
\hline Inversões Financeiras & 1 & 0 & 1 & 0 \\
\hline TOTAL & 105.102 & 48.761 & 56.341 & 46,4 \\
\hline
\end{tabular}

Fonte: Sistema de Programação e Execução Orçamentária e Financeira (SIOFI-NET/SCP NET/SEFAZ/GO) (SIOFI, s. d.).

Observando a previsão orçamentária atualizada, fornecida pela Secretaria da Fazenda do Estado, no Relatório Resumido da Execução Financeira, constatamos que houve uma correção no orçamento para a UEG, totalizando $\mathrm{R} \$ 105.102 .000,00$. Em relação aos recursos para provimento das despesas, que por força de lei deveriam ser repassados à universidade, verificou-se até o $6^{\circ}$ bimestre, ou seja, até dezembro de 2005 , a execução de $R \$ 48,7$ milhões.

Conforme demonstrado na Tabela 3, que apresenta a movimentação de recursos da UEG de acordo com a previsão orçamentária, os repasses não se efetivaram na totalidade, demonstrando um contingenciamento da ordem de 53,6\%. Nota-se que as despesas para pagamento de pessoal e encargos sociais atingiram quase a totalidade da previsão orçamentária, entretanto, os recursos orçados para investimentos atingiram pouco mais de $7 \%$. Compreende-se que as atividades-meio acabam por interferir nas atividades-fim, o que significa dizer que as condições físicas e estruturais das Unidades Universitárias (adequação de prédios, equipamentos, ampliações dos espaços físicos, entre outras) interferem nos resultados finais do processo de aprendizagem, em qualquer nível ou modalidade de ensino. 
Aplicação dos Recursos em Educação Básica

A universidade contou com recursos próprios e de convênios que totalizaram até o mês de novembro, segundo Relatório da Diretoria de Planejamento da UEG, R\$20.294.477,68, e $\mathrm{R} \$$ 43.060.195,22 oriundos do Tesouro Estadual, totalizando $\mathrm{R} \$ 63.354 .672,90$. Significa dizer que os recursos próprios e de convênios representaram cerca de $50 \%$ do valor executado pelo Tesouro Estadual e $30 \%$ dos recursos totais utilizados para a manutenção da universidade até essa data, incluindo os repasses para as 30 Unidades Universitárias. 0 contingenciamento dos recursos previstos para a UEG até o mês de dezembro acabou por se constituir em um aspecto negativo, reafirmando que as ações do governo explicitadas nas políticas públicas para a educação não saíram do campo das intenções, uma vez que na realidade não se efetivaram.

O investimento na Educação Básica a partir dessa última alteração da legislação ainda apresenta índices abaixo do que determina a $\mathrm{CE}$, pois continua a incluir para efeito de cálculo as despesas com pagamento de inativos e pensionistas.

\section{Tabela 5 - Percentual de Gastos com a Educação Básica - Goiás 2006-2008}

\begin{tabular}{|c|c|c|}
\hline Ano & $\begin{array}{c}\text { Percentual aplicado incluindo inativos e } \\
\text { pensionistas }\end{array}$ & $\begin{array}{c}\text { Percentual aplicado exceto inativos e } \\
\text { pensionistas }\end{array}$ \\
\hline 2006 & 27,17 & 22,35 \\
\hline 2007 & 25,30 & 20,83 \\
\hline 2008 & 23,73 & 20,13 \\
\hline
\end{tabular}

Fonte: Tribunal de Contas do Estado de Goiás.

As manobras políticas realizadas pelo governo no sentido de garantir legalidade aos seus atos, em detrimento das conquistas da sociedade, vão se distanciando de uma política pública que prima pelos direitos sociais. O TCE, ao analisar as contas de Governo de 2008, alerta para o não atendimento dos preceitos legais, ressaltando em parecer:

[...] não atendimento de recomendação deste Tribunal, nas contas de 2008, de elaboração de um plano de exclusão das despesas com pagamento de inativos, da base de cálculos do valor aplicado em Manutenção e Desenvolvimento do Ensino, em respeito ao disposto no art. 212 da Constituição Federal (TCE, 2008, p. 2).

Caminhando para o atendimento da ressalva emitida pelo TCE, em 2009 o governo consegue a aprovação da EC $n^{\circ} 43$ de 12 de maio, que altera o art. 158, acrescendo o parágrafo $5^{\circ}$, consolidando nova derrota para a educação em Goiás, corroborando, nesse sentido, para um retrocesso histórico do ponto de vista do financiamento da educação. Diz o parágrafo: "Para cumprimento dos percentuais previstos nos incisos I a IV, serão consideradas as despesas com pessoal do corpo docente e técnico administrativo ativo e inativo" (GOIÁS, 2009). A partir desse momento, os investimentos em educação no Estado incluem as despesas com os funcionários inativos e pensionistas, restando menos recursos para o investimento na Educação Básica. Ainda assim, os dados nos anos seguintes não atingem na totalidade os índices previstos em Lei. 
Aplicação dos Recursos em Educação Básica

Tabela 6 - Percentual de Gastos com a Educação Básica - Goiás 2009-2015 (\%)

\begin{tabular}{|c|c|c|}
\hline Ano & Percentual aplicado incluindo inativos e pensionistas & Contas Revisadas $^{5}$ \\
\hline 2009 & 25,50 & \\
\hline 2010 & 27,22 & \\
\hline 2011 & 24,93 & 25,05 \\
\hline 2012 & 25,05 & \\
\hline 2013 & 25.03 & \\
\hline 2014 & 25,68 & \\
\hline 2015 & 24,95 & \\
\hline
\end{tabular}

Fonte: Tribunal de Contas do Estado de Goiás.

Ao analisarmos as contas de governo, constatamos que nesses últimos sete anos o percentual de recursos para a educação se manteve nos 25\%, com exceção do ano de 2010 , que ultrapassou o percentual (trata-se de um ano eleitoral, portanto atípico), e o ano de 2015, que ficou abaixo do previsto em lei. No entanto, a estratégia utilizada desde 2009 , quando foi aprovada uma lei que permite a inclusão das despesas com aposentados e pensionistas no percentual de aplicação da educação, e a permissão do TCE para que, nos três primeiros anos, partir do ano subsequente, possam ser realizados ajustes nas contas de governo, configuram-se em ações políticas que legalizam investimentos em educação a menor do que determina a legislação.

\section{Considerações Finais}

A reflexão com base nos dados ora explicitados nos remonta às questões de ordem política, uma vez que o fracasso ou o sucesso do desempenho de nossos alunos passa, em grande medida, pela política educacional desenvolvida no Brasil historicamente.

$\mathrm{Na}$ atualidade, o discurso dos governos e dos empresários (classe dominante) tem frequentemente apontado a educação como fator determinante de desenvolvimento econômico do país. Entretanto, as políticas públicas e os investimentos em educação, principalmente na Educação Básica, não têm propiciado as possibilidades de qualificação do trabalhador para enfrentar a complexificação crescente dos processos de trabalho da $3^{a}$ Revolução Industrial (tecnologias da informática, microeletrônica e outras técnicas afins).

Os estudos que viemos realizando na direção de compreender as políticas públicas têm nos indicado que a locação de recursos para o financiamento da educação interfere de forma expressiva no resultado do processo educacional. É desejável e direito, expresso pela Constituição Federal, de todos os brasileiros, uma educação de qualidade, garantida por acesso e permanência pelo menos na Educação Básica. Consta ainda na Constituição, como outras Leis complementares, que o sistema de ensino deve garantir condições para prosseguimento de estudos.

O Estado de Goiás conseguiu, por um curto período, ampliar esses investimentos, possibilitando ações mais consistentes para a Educação Básica. Em um momento em que a sociedade brasileira vivenciou a conquista de um percentual fixo de recursos para a educação, Goiás, em 1989 , deu um salto de $25 \%$ para $30 \%$ na garantia desses percentuais, ampliando

5 Até a data deste estudo, apenas o ano de 2011 teve as Contas de Governo revisadas pelo TCE, com alteração do percentual gasto com a Educação Básica. 
Aplicação dos Recursos em Educação Básica

o investimento de recursos para a educação pública. Entretanto, essa conquista não prosseguiu nas políticas públicas que se sucederam, e a Educação Básica em Goiás não difere da média nacional, cujos resultados nos colocam em permanente atenção. Diante de uma política pública tímida no tocante à locação de recursos, evidenciam-se as dificuldades que a educação brasileira, assim como a goiana, vêm enfrentando para romper com os baixos resultados nos diferentes programas de avaliação interna e externa.

Reconhecemos que, embora a sociedade brasileira venha de longa data lutando para ver seus direitos respeitados e consolidados por meio de políticas públicas e dispositivos legais que garantam a destinação de recursos para uma oferta de educação de qualidade, encontramo-nos ainda diante de resultados insuficientes.

O retrocesso em Goiás é marcado por estratégias políticas de legitimação de práticas de gestão equivocadas e que caminham na contramão das reivindicações históricas da sociedade, no sentido de garantir a vinculação de recursos para a educação. Essas estratégias são aceitas e confirmadas por setores do poder que têm a priori a incumbência de fiscalizar as contas públicas. Esse movimento contraditório evidencia o descaso de fato com a educação, embora os discursos alardeiem uma preocupação com a educação como direito público subjetivo.

O Estado de Goiás precisa rever suas políticas públicas educacionais, com vistas a superar os desafios postos para a educação no país. Essa revisão passa, com certeza, pelo cumprimento da legislação e pela manutenção de conquistas históricas, além da não degradação dos pequenos passos dados.

Finalmente, concluído este estudo, chamamos a atenção para a necessidade de ações de natureza eminentemente políticas da população para que o Estado venha a cumprir a legislação vigente, quanto ao percentual de aplicação de $25 \%$, sem incluir os recursos destinados ao pagamento dos aposentados e pensionistas, que distorcem a aplicação em educação. Precisamos contribuir para a transformação da realidade observada, na construção de uma gestão pública transparente que cumpra a legislação.

\section{Referências}

BRASIL. Constituição da República Federativa do Brasil. Diário Oficial da União, Brasília, 05 out. 1988.

BRASIL. Lei no 9.394 de 20 de dezembro de 1996. Estabelece as Diretrizes e Bases da Educação Nacional. Diário Oficial da União, Brasília, 1996. Disponível em: <http://www.planalto.gov.br/ccivil_03/leis/L9394.htm>. Acesso em: 20 fev. 2017.

BRASIL. Ministério da Educação (MEC). Investimento Público em Educação. Brasília: INEP, 2008.

BRASIL. Lei no 13.005 de 25 de junho de 2014. Aprova o Plano Nacional de Educação PNE e dá outras providências. Diário Oficial da União, Brasília, Senado Federal, 2014. Disponível em: <http://www.planalto.gov.br/ccivil_03/_ato2011-2014/2014/lei/l13005.htm>. Acesso em: 20 fev. 2016. 
Aplicação dos Recursos em Educação Básica

BRASIL. Síntese dos Indicadores: uma análise das condições de vida da população brasileira. Rio de Janeiro: IBGE, 2016. Disponível em: <http://www.ibge.gov.br>. Acesso em: 20 maio 2017.

BRUNO, Lúcia. Educação, Qualificação e Desenvolvimento Econômico. In: BRUNO, Lúcia (Org.). Educação e Trabalho no Capitalismo Contemporâneo: leituras selecionadas. São Paulo: Atlas, 1996.

CURY. Carlos Roberto Jamil. Financiamento da Educação Brasileira: do subsídio literário ao Fundeb. Belo Horizonte: PUC-Minas, s. d. Disponível em: $<$ http://www2.camara.leg.br/atividade-legislativa/comissoes/comissoes-temporarias lespeciais/55a-legislatura/pec-015-15-torna-permanente-o-fundeb-educacao/docu mentos/audiencias-publicas/FinanciamentoEBCarlosRobertoJamil Cury.pdf>. Acesso em: 28 maio 2017.

GOIÁS. Constituição Estadual do estado de Goiás. Diário Oficial da Assembleia do Estado de Goiás, Goiânia, 1989. Disponível em: <http://www.gabinetecivil.goias.gov.br/constituicoes/ constituicao_1988.htm>. Acesso em: 4 maio 2017.

GOIÁS. Lei Complementar $n^{\circ} 26$, de 28 de dezembro de 1998. Estabelece as diretrizes e bases do Sistema Educativo do Estado de Goiás. Diário Oficial do Estado de Goiás, Goiânia, 1998. Disponível em: <http://www.gabinetecivil.goias.gov.br/leis_complementares/ 1998/lei_complementar_n26.htm>. Acesso em: 4 maio 2017.

GOIÁS. Emenda Constitucional n 33, de 02 de Janeiro de 2003. Altera os dispositivos da Constituição do Estado de Goiás que especifica Diário Oficial da Assembleia do Estado de Goiás, Goiânia, 2003. Disponível em: <http://www.gabinetecivil.goias.gov.br/ pagina_emendas.php?id=35>. Acesso em: 4 maio 2017.

GOIÁS. Secretária da Fazenda do Estado de Goiás. Relatório Resumido da Execução

Financeira. Goiânia, 2005.2017 Disponível
<http://www.sefaz.go.gov.br/GestãoFiscal/GestãoFisacal2005>. Acesso em: 21 jun. 2017.

GOIÁS. Emenda Constitucional $n^{\circ} 43$, de 12 de maio de 2009. Altera os dispositivos da Constituição Estadual que especifica. Diário Oficial da Assembleia do Estado de Goiás, Goiânia, 2009. Disponível em: <http://www.gabinetecivil.go.gov.br/ pagina_emendas.php?id=76>. Acesso em: 28 jun. 2017.

MESQUITA, Cristina das Graças Dutra. Política Pública de Financiamento da Educação Infantil no Estado de Goiás: o desvelamento do real. 2005. 120 f. Dissertação (Mestrado em Educação) - Universidade Católica de Goiás, Goiânia, 2005.

MESQUITA, Maria Cristina das Graças Dutra. O Trabalhador Estudante do Ensino Superior Noturno: possibilidades de acesso, permanência com sucesso e formação. 2010. Tese (Doutorado em Educação) - Pontifícia Universidade Católica de Goiás, Goiânia, 2010.

MESQUITA, Maria Cristina das Graças Dutra Mesquita; CARNEIRO, Maria Esperança Fernandes. Revendo os Dados e as Concepções: retrocesso no financiamento da educação em Goiás. SIMPÓSIO BRASILEIRO, 23., CONGRESSO LUSO-BRASILEIRO, 5., COLÓQUIO IBERO-AMERICANO DE POLÍTICA E ADMINISTRAÇÃO DA EDUCAÇÃO, 1., Caderno Anpae... Goiânia: Universidade Federal de Goiás, 2007. 
Aplicação dos Recursos em Educação Básica

SIOFI, Sistema de Programação e Execução Orçamentária e Financeira. Relatório Resumido da Execução Financeira. Goiânia: Secretaria da Fazenda do Estado de Goiás, s. d.

Maria Cristina Dutra Mesquita possui graduação em Pedagogia, mestrado em Educação e doutorado pela Pontifícia Universidade Católica de Goiás (PUC-Goiás). Atualmente é professora da PUC-Goiás e integra o Programa de Pós-Graduação e Pesquisa em Educação da PUC-Goiás.

E-mail: mcristinadm@yahoo.com.br

Maria Esperança Fernandes Carneiro possui graduação em História e mestrado em História pela Universidade Federal de Goiás (UFG) e doutorado em Educação: História, Política e Sociedade pela Pontifícia Universidade Católica de São Paulo (PUC-SP). Atualmente é professora titular da PUC-Goiás no Programa de Pós-Graduação em Educação.

E-mail: esperancacarneiro@outlook.com

Lucia Helena Rincon Afonso possui graduação em História e mestrado em História Regional pela Universidade Federal de Goiás (UFG) e doutorado em Educação pela Universidade Estadual Paulista Júlio de Mesquita Filho. Atualmente é professora da PUC-Goiás.

E-mail: luciarincon@gmail.com 


\section{Editores do volume 7}

José Marcelino de Rezende Pinto - Universidade de São Paulo, São Paulo/SP, Brasil

Nalú Farenzena - Universidade Federal do Rio Grande do Sul, Porto Alegre/RS, Brasil

\section{Comitê Editorial}

José Marcelino de Rezende Pinto - Universidade de São Paulo, Brasil

Juca Gil - Universidade Federal do Rio Grande do Sul, Brasil

Theresa Adrião - Universidade Estadual de Campinas, Brasil

Ângelo Ricardo de Souza - Universidade Federal do Paraná, Brasil

Márcia Aparecida Jacomini - Universidade Federal de São Paulo, Brasil

\section{Conselho Editorial}

\section{Alejandro Morduchowicz}

Universidad Pedagógica, Provincia de Buenos Aires, Argentina

Fernanda Saforcada

Universidade de Buenos Aires, Argentina

Jacques Velloso

Universidade de Brasília, Brasil

João Monlevade

Senado Federal, Brasil

Jorge Abrahão de Castro

Instituto de Pesquisa Econômica Aplicada / IPEA, Brasil

Juca Gil

Universidade Federal do Rio Grande do Sul, Brasil

Lisete Regina Gomes Arelaro

Universidade de São Paulo, Brasil

Luis Carlos Sales

Universidade Federal do Piauí, Brasil

Luiz de Sousa Junior

Universidade Federal da Paraíba, Brasil

Luiz Fernandes Dourado

Universidade Federal de Goiás, Brasil

Magna França

Universidade Federal do Rio Grande do Norte, Brasil

Maria Beatriz Luce

Universidade Federal do Pampa, Brasil

Universidade Federal do Rio Grande do Sul, Brasil

Marcos Edgar Bassi

Universidade Federal do Paraná, Brasil

Maria Dilnéia Espíndola Fernandes

Universidade Federal de Mato Grosso do Sul, Brasil

\section{Nalú Farenzena}

Universidade Federal do Rio Grande do Sul, Brasil

Nelson Cardoso do Amaral

Universidade Federal de Goiás, Brasil

Nicholas Davies

Universidade Federal Fluminense, Brasil

Rosana Evangelista Cruz

Universidade Federal do Piauí, Brasil

Rosana Gemaque

Universidade Federal do Pará, Brasil

Robert E. Verhine

Universidade Federal da Bahia, Brasil

Romualdo Portela de Oliveira

Universidade de São Paulo, Brasil

Theresa Adrião

Universidade Estadual de Campinas, Brasil

Tristan McCowan

University of London, Reino Unido

Vera Jacob

Universidade Federal do Pará, Brasil

Vera Peroni

Universidade Federal do Rio Grande do Sul, Brasil

Vitor Henrique Paro

Universidade de São Paulo, Brasil

\section{Equipe editorial}

Apoio ao Comitê Editorial: Patrícia Balthazar Garcia

Diagramação, Revisão de português e normalização: Edson Leonel de Oliveira

Revisão de inglês: Ananyr Porto Fajardo 